\title{
Immunoblotting as a confirmatory test for antimitochondrial antibodies in primary biliary cirrhosis
}

\author{
G Provenzano, O Diquattro, A Craxì, P Almasio, G Pinzello, L Marino, G Fiorentino, \\ F Rinaldi, L Pagliaro
}

\begin{abstract}
Primary biliary cirrhosis is characterised by the presence of antimitochondrial antibodies which are directed against components of mitochondrial dehydrogenase complexes. The specificity of antimitochondrial antibodies for primary biliary cirrhosis as detected by immunoblotting was investigated. Commercially available preparations of pyruvate and oxo-glutarate dehydrogenases and beef-heart mitochondria were used as source of antigens. Sera from 47 primary biliary cirrhosis patients (46 of whom were antimitochondrial antibody positive by immunofluorescence), 16 non-primary biliary cirrhosis patients (antimitochondrial antibody positive by immunofluorescence), 23 liver-kidney microsomal antibody positive chronic active hepatitis patients, and 32 patients with connective tissue diseases were examined. Of the 47 subjects with primary biliary cirrhosis, $43(91 \%)$ and $13(28 \%)$ tested positive by immunoblotting for pyruvate and oxo-glutarate dehydrogenase, respectively. Only three primary biliary cirrhosis patients were negative for both antigens, including the only one shown to be antimitochondrial antibody negative by immunofluorescence. The other two patients were positive by immunoblotting with beef-heart mitochondria. In contrast, only three of $16(19 \%)$ non-primary biliary cirrhosis patients who were antimitochondrial antibody positive by immunofluorescence tested positive by immunoblotting (for both pyruvate dehydrogenase and beef-heart mitochondria). None of the 23 liver-kidney microsomal antibody positive and the 32 patients with rheumatic diseases were positive by immunoblotting with any antigen. Our data show that immunoblotting with commercially available oxo-acid dehydrogenases is a reproducible method for the detection of antimitochondrial antibodies highly specific for primary biliary cirrhosis.

(Gut 1993; 34: 544-548)
\end{abstract}

Primary biliary cirrhosis is a chronic autoimmune liver disease of unknown aetiology characterised by progressive inflammatory obliteration of intrahepatic bile ducts, leading to fibrosis, liver cell damage, and ultimately to cirrhosis.'

A common feature of the disorder is the occurrence of antimitochondrial antibodies, which are found in about $95 \%$ of sera from primary biliary cirrhosis patients and are widely used as an aid to diagnosis. ' The method routinely used for their detection is immunofluorescence. Nevertheless, this technique lacks diagnostic specificity since it can be positive in other disorders - for example, rheumatoid arthritis, cardiomyopathy, and systemic lupus erythematosus. ${ }^{3}$ More detailed analyses of antimitochondrial antibodies, carried out by use of mitochondrial membrane preparations and western immunoblots, has identified a range of patterns (M1-M9), among which $M 2$ is reported to be typical and specific for primary biliary cirrhosis. $^{3}$

Antimitochondrial antibodies M2 are directed against trypsin-sensitive antigens associated with the inner mitochondrial membrane. ${ }^{+}$Recently, six M2 antigens have been identified as components of the 2-oxo acid dehydrogenase multienzyme complexes located within mammalian mitochondria (Table I) and the E2 component (dihydrolipoamide acetyltransferase) and the so called protein $\mathrm{X}$ of pyruvate dehydrogenase complex are known to be the major autoantigens. ${ }^{3}$

Further subtypes of antimitochondrial antibodies, namely M4, M8, and M9, have been reported to be associated with primary biliary cirrhosis and have been characterised by complement fixation test and ELISA using semipurified subfractions of mitochondria. ${ }^{+}$Recent findings concerning their biochemical identities $^{1+15}$ need to be validated, hence it seems premature to assess their diagnostic value in primary biliary cirrhosis.

This study aimed to investigate the specificity for primary biliary cirrhosis of antimitochondrial antibody $\mathrm{M} 2$ detected by immunoblotting, using commercially available preparations of pyruvate and oxo-glutarate dehydrogenase complexes as sources of antigen. We have tested antimitochondrial antibody positive sera, as assessed by immunofluorescence, from two groups of patients - those with well defined primary biliary cirrhosis and subjects without clinical or biochemical evidence of this disorder.

\section{Methods}

\section{PATIENTS}

A total of 118 serum samples were studied. They were obtained from four groups of patients:

(1) Forty seven patients with primary biliary cirrhosis, all but one of whom were women. In all cases the diagnosis was based on clinical, biochemical, and histological data. ${ }^{16}$ Only one patient was antimitochondrial antibody negative by immunofluorescence. Eighteen were 
TABLE I M2 autoantigens ${ }^{\star}$

\begin{tabular}{lll}
\hline $\begin{array}{l}\text { Molecular weight } \\
(k D a)\end{array}$ & Identity & $\begin{array}{l}\text { \% Antibody }+v e \\
\text { in PBC }\end{array}$ \\
\hline $68-74$ & PDH-E2 & $80-95$ \\
$50-56$ & Protein X & $80-95$ \\
$50-52$ & BCODH-E2 & $30-50$ \\
$46-48$ & OGDH-E2 & $30-60$ \\
$39-45$ & PDH-El $\alpha$ & $40-70$ \\
$34-36$ & PDH-E1 $\beta$ & $<5$ \\
\hline
\end{tabular}

$\mathrm{PDH}=$ pyruvate dehydrogenase $; \mathrm{BCODH}=$ branched-chain oxoacid dehydrogenase; $\mathrm{OGDH}=0 \times 0$-acid glutamic dehydrogenase $\star$ References 5-13. + By immunoblotting. Discrepancies reported in molecular weight reflect empirical differences in techniques.

diagnosed during the period 1 October 1989 to 30 September 1991 (all these were antimitochondrial antibody positive).

(2) Sixteen sera shown to be antimitochondrial antibody positive by immunofluorescence from subjects without clinical and laboratory evidence of primary biliary cirrhosis. Samples were sent consecutively to our laboratory between 1 October 1989 and 30 September 1991 for autoantibodies testing. The subjects' medical records were available for further analysis. Eight of them had chronic liver diseases of different aetiologies (five hepatitis $\mathrm{C}$ virus related, one autoimmune, one hepatitis B virus with delta virus superinfection, one protracted acute hepatitis of undefined aetiology). The remaining eight patients did not show any clinical or biochemical feature of liver damage: three had connective tissue diseases, one rheumatoid arthritis, one antiphospholipid antibody syndrome, one Graves's disease, one visceral Leishmaniosis, and one metastatic lung cancer.

(3) Twenty three liver-kidney microsomal antibody positive patients with biopsy proved chronic active hepatitis.

(4) Thirty two sera shown to be antimitochondrial antibody negative by immunofluorescence from patients with well characterised connective tissue diseases and a variety of autoantibodies (predominantly antinuclear antibody and/or rheumatoid factor). Thirteen patients had systemic lupus erythematosus, 10 rheumatoid arthritis, two progressive systemic sclerosis, two polymyositis, four mixed connective tissue diseases, and one primary Sjögren's syndrome.

\section{IMMUNOFLUORESCENCE}

Antimitochondrial as well as antinuclear and liver-kidney microsomal antibodies were initially detected by the standard indirect immunofluorescence technique using both commercially available cryostat sections of rat liver, kidney, and stomach (Bio System, Italy and Hep-2 cell slides (Ortho Diagnostic Systems, Raritan NJ, USA). The screening dilution of the sera was $1: 40$ in phosphate buffered saline. Antimitochondrial antibodies were titrated by serial dilution to $1: 320$. A fluorescence isothiocyanate conjugated goat anti-human IgG was used as a second antibody. Slides were read under a Leitz Orthoplan microscope with vertical illumination.

IMMUNOBLOTTING

Commercially available preparations of pyruvate and oxo-glutarate dehydrogenase complexes (Sigma Chemicals, USA) and a preparation of beef-heart mitochondria, kindly provided by $\mathrm{Dr}$ M Fusconi and Professor F B Bianchi, were used as sources of antigens.

The immunoblotting procedure was identical for all antigens. They were incubated for $1 \frac{1 / 2}{2}$ hours at $37^{\circ} \mathrm{C}$ in $125 \mathrm{mM}$ Tris- $\mathrm{HCl} \mathrm{pH} \mathrm{6.8,} 2 \mathrm{mM}$ EDTA, 2\% sodium dodecylsulphate, and 50 $\mathrm{mM}$ dithiothreitol. Final concentrations of antigens were $0.56 \mathrm{mg} / \mathrm{ml}$ for pyruvate dehydrogenase, $0.66 \mathrm{mg} / \mathrm{ml}$ for oxo-glutarate dehydrogenase, and $2 \cdot 2 \mathrm{mg} / \mathrm{ml}$ for beef-heart mitochondria. Bromophenol blue was then added (to a concentration of $0.01 \%$ ) and the samples were submitted to sodium dodecylsulphate polyacrylamide $(10 \%)$ gel electrophoresis according to $\mathrm{Laemmli}^{17}$ until the dye font had migrated $13 \mathrm{~cm}$.

The molecular weight standards (Sigma Chemicals, USA) for determination of the molecular weights of the reacting peptides were treated in the same way. They were $\alpha 2$-macroglobulin $(180 \mathrm{kDa}), \beta$-galactosidase $(116 \mathrm{kDa})$, fructose-6-P-kinase $(84 \mathrm{kDa})$, pyruvate kinase $(58 \mathrm{kDa})$, fumarase $(48.5 \mathrm{kDa})$, lactic dehydrogenase $(36.5 \mathrm{kDa})$, and triosephosphate isomerase $(26.6 \mathrm{kDa})$. The proteins in the gel were then transblotted on to a nitrocellulose sheet (pore size $0.45 \mu \mathrm{m}$, Pharmacia LKB Biotechnology, Sweden) according to Towbin et al. ${ }^{18}$

Before being used in immunoblotting experiments, the nitrocellulose was blocked with 3\% dry milk powder in Tris buffered saline (TBS: 20 $\mathrm{mM}$ Tris- $\mathrm{HCl}, \mathrm{NaCl} 0.9 \% \mathrm{pH} \mathrm{7 \cdot 5)}$ for $1 \frac{1}{2}$ hours at $37^{\circ} \mathrm{C}$ and agitated gently. Then it was washed twice in TBS and incubated for $11 / 2$ hours at $37^{\circ} \mathrm{C}$ with sera diluted 1:100 and 1:500 in TBS with $3 \%$ dry milk powder. Some positive sera were further diluted to $1: 1000$. The nitrocellulose was then washed three times for 10 minutes each with TBS, and incubated with anti-human total immunoglobulins peroxidase conjugated antiserum (Dakopatts, Denmark) diluted 1:1000 in TBS and dry milk powder for 1 hour at $37^{\circ} \mathrm{C}$. After three washings of 10 minutes each, the peroxidase was developed with $0.05 \% 3,3^{\prime}$ diaminobenzidin (Bio-Rad Laboratories, USA)

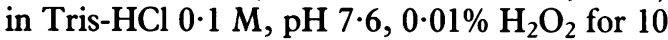
minutes at room temperature. All sera were tested twice.

\section{Results}

Antimitochondrial antibody titres as assessed by immunofluorescence, were greater than 1:160 in all positive patients with primary biliary cirrhosis but in only six of $16(37 \cdot 5 \%)$ of all other patients.

Immunoblotting results are summarised in Table II. Results were equivalent at both 1:100 and 1:500 with no significant 'background' staining.

Using pyruvate dehydrogenase as antigenic substrate, $91 \%$ of primary biliary cirrhosis sera were reactive. All positive sera showed reactivity at $72 \mathrm{kDa}$, and 39 of $47(83 \%)$ were also positive at $51 \mathrm{kDa}$. Twenty two (47\%) sera showed an additional reactivity at $39 \mathrm{kDa}$ (see Table III and figure). 
TABLE II Frequencies of positivity by immunoblotting

\begin{tabular}{lll}
\hline & $\begin{array}{l}\text { Pyruvate and/or oxo- } \\
\text { glutarate dehydrogenase }\end{array}$ & $\begin{array}{l}\text { Beef-heart } \\
\text { mitochondria }\end{array}$ \\
\hline PBC $(n=47)^{\star}$ & $44(94 \%)$ & $46(98 \%)$ \\
Non-PBC AMA $(n=16)$ & $3(19 \%)$ & $3(19 \%)$ \\
CAH LKMA $(n=23)$ & - & - \\
CTD $(n=32)$ & - & -
\end{tabular}

$\mathrm{CAH}=$ chronic active hepatitis; LKMA = liver-kidney microsomal antibody; CTD $=$ connective tissue disease;

AMA = antimitochondrial antibody. ${ }^{\star}$ The single patient AMA negative by immunofluorescence was also non-reactive by immunoblotting with all three antigen preparations.

TABLE III Frequencies of bands detected by immunoblotting with pyruvate dehydrogenase $(P D H)$, oxo-glutarate dehydrogenase $(O G D H)$, and beef-heart mitochondria $(B H M)$ in 47 patients with primary biliary cirrhosis

\begin{tabular}{|c|c|c|c|c|c|}
\hline & \multirow{2}{*}{$\begin{array}{l}\text { Positive for } \\
\text { any band }\end{array}$} & \multicolumn{4}{|l|}{ Band } \\
\hline & & $72 k D a$ & $51 k D a$ & $45 k D a$ & $39 k D a$ \\
\hline PDH & $43(91 \%)$ & $43(91 \%)$ & $39(83 \%)$ & - & $22(47 \%)$ \\
\hline OGDH & $13(28 \%)$ & - & - & $13(28 \%)$ & \\
\hline BHM & $46(98 \%)$ & $43(91 \%)$ & $42(89 \%)$ & $9(19 \%)$ & $22(47 \%)$ \\
\hline
\end{tabular}

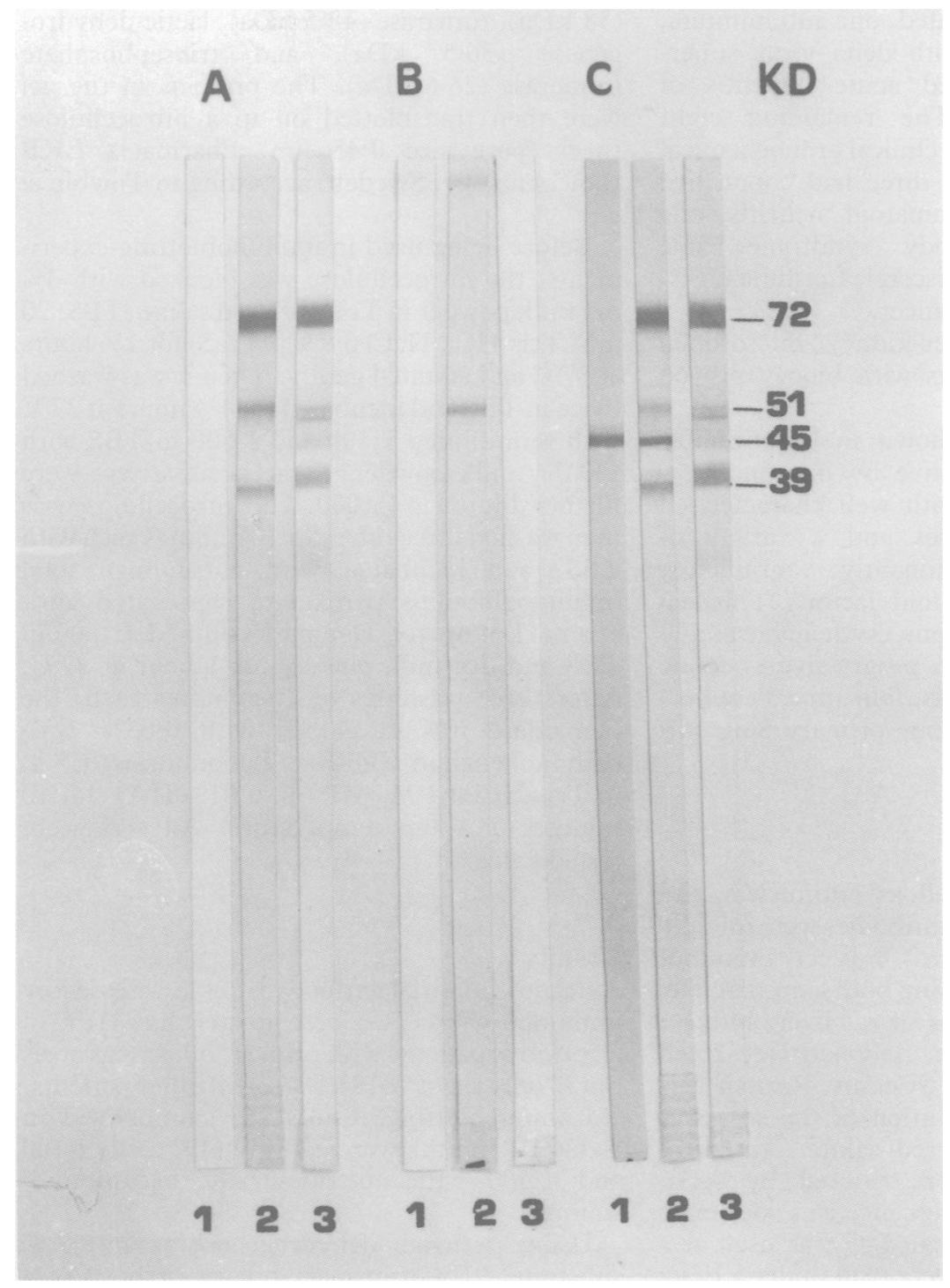

Immunoblotting of antimitochondrial antibody positive primary biliary cirrhosis sera $(A, B, C)$ with oxo-glutarate dehydrogenase (lane 1 ), beef-heart mitochondria (lane 2), and pyruvate dehydrogenase (lane 3). (A) Reactive at 72, 51 and $39 \mathrm{kDa}$ with beef-heart mitochondria and pyruvate dehydrogenase; unreactive with oxo-glutarate dehydrogenase. $(B)$ Reacts only with beef-heart mitochondria at $51 \mathrm{kDa}$. (C) Additional reactivity at $45 \mathrm{kDa}$ with beef-heart mitochondria and oxo-glutarate dehydrogenase.
TABLE IV Non-primary biliary cirrhosis patients shown to be antimitochondrial antibody (AMA) positive by immunoblotting $(I B)$

\begin{tabular}{lllll}
\hline Sex & Age $(y)$ & Diagnosis & AMA titre & IB pattern\# \\
\hline $\mathrm{F}$ & 43 & Rheumatoid arthritis & $1: 160$ & $72 \mathrm{kD}$ \\
$\mathrm{F}$ & 56 & Graves's disease & $1: 80$ & $72,51 \mathrm{kD}$ \\
$\mathrm{F}$ & 59 & Autoimmune CAH & $1: 320$ & $72,51 \mathrm{kD}$
\end{tabular}

$\mathrm{CAH}=$ chronic active hepatitis. ${ }^{\star} \mathrm{By}$ immunofluorescence testing. \# With beef-heart mitochondria and pyruvate dehydrogenase.

Thirteeen $(28 \%)$ primary biliary cirrhosis sera reacted with oxo-glutarate dehydrogenase, all at $45 \mathrm{kDa}$ (see Table III and figure). One of these 13 sera was negative with pyruvate dehydrogenase.

Only three primary biliary cirrhosis sera tested were negative with both pyruvate and oxoglutarate dehydrogenases, including the single sample that was antimitochondrial antibody, negative by immunofluorescence.

When beef-heart mitochondria were used, all primary biliary cirrhosis sera that had been antimitochondrial antibody positive by immunofluorescence, were confirmed as positive (see Table III and figure). The two samples that were antimitochondrial antibody positive by immunofluorescence but negative by immunoblotting with both pyruvate and oxo-glutarate dehydrogenases, exhibited a single reactivity at $51 \mathrm{kDa}$ when tested with beef-heart mitochondria. The single serum that was reactive with oxo-glutarate dehydrogenase but not with pyruvate dehydrogenase reacted at 51 and 45 $\mathrm{kDa}$ with beef-heart mitochondria. In all other primary biliary cirrhosis cases, the pattern of reactivity to 72,51 , and $39 \mathrm{kDa}$ was comparable using beef-heart mitochondria and pyruvate dehydrogenase. The nine samples that showed an additional reactivity at $45 \mathrm{kDa}$ with beef-heart mitochondria all reacted with oxo-glutarate dehydrogenase. The single primary biliary cirrhosis patient who was antimitochondrial antibody negative by immunofluorescence was also negative by immunoblotting with all the three antigen preparations.

Among non-primary biliary cirrhosis patients who were antimitochondrial antibody positive by immunofluorescence, only three (19\%) were positive by immunoblotting (with pyruvate dehydrogenase and beef-heart mitochondria). All three sera were still positive when diluted $1: 1000$ (a similar titre to that observed in 10 patients with primary biliary cirrhosis). The immunoblotting pattern of positivity and the main features of these three patients are shown in Table IV. Two of them did not show any clinical or biochemical features of liver damage.

No other sera (23 with liver-kidney microsomal antibody positive chronic hepatitis and 32 with rheumatic diseases) showed any reactivity by immunoblotting with any of the three antigen preparations used.

\section{Discussion}

Antimitochondrial antibodies are found in almost all patients with primary biliary cirrhosis. Their detection is strongly suggestive of primary biliary cirrhosis, even in the presence of a normal alkaline phosphatase activity. ${ }^{1020}$ It has been 
shown, however, that in the absence of compatible clinical features, a positive antimitochondrial antibody test alone (by standard immunofluorescence) is not entirely specific for primary biliary cirrhosis. ${ }^{21}$ Antibodies to mitochondria are a heterogeneous group that contains multiple specificities, and they may also be present in the serum of apparently healthy individuals. ${ }^{22}$ Moreover, the immunofluorescence technique requires recognition of a characteristic pattern of staining on composite tissue blocks and is therefore largely dependent on the observer's skill.

Our immunoblotting results with the commercially available mitochondrial dehydrogenase complexes show that immunoblotting is a reproducible tool for the detection of antimitochondrial antibody specific for primary biliary cirrhosis. The sensitivity for detecting antimitochondrial antibody in primary biliary cirrhosis was $94 \%$ by immunoblotting, slightly less than that obtained by immunofluorescence $(98 \%)$.

All subjects with liver-kidney microsomal antibody positive chronic active hepatitis and patients with rheumatic diseases were negative by immunoblotting with all antigens (including beef-heart mitochondria). This confirms the high specificity of the technique. It is noteworthy that the inexperienced observer may find the liver-kidney microscomal antibody difficult to discriminate from antimitochondrial antibody.

The pattern of immunoblotting reactivity in positive sera confirmed data by other authors. ${ }^{6-10}$ All sera that reacted with pyruvate dehydrogenase $(91 \%$ of primary biliary cirrhosis and $19 \%$ of non-primary biliary cirrhosis sera) showed positivity for a $72 \mathrm{kDa}$ band. It is widely recognised that the E2 component of pyruvate dehydrogenase, namely the predominant M2 autoantigen in primary biliary cirrhosis, has a molecular weight of approximately 68-74 $\mathrm{kDa} .{ }^{6710}$ The $51 \mathrm{kDa}$ reactivity present in all but five sera immunoblotting positive with pyruvate dehydrogenase (four primary biliary cirrhosis and one non-primary biliary cirrhosis patients), is probably related to the so-called protein $\mathrm{X}$ of pyruvate dehydrogenase. Its reported molecular weight is $50-56 \mathrm{kDa}$ and previous studies have shown that almost all sera that react with the E2 component of pyruvate dehydrogenase also recognize protein $\mathrm{X}^{67}$ Molecular weight (39 $\mathrm{kDa}$ ) and prevalence of positivity in primary biliary cirrhosis $(47 \%)$ suggest that the third immunoreactive peptide corresponds to the El $\alpha$ component of pyruvate dehydrogenase complex. ${ }^{9}$ All sera reactive with oxo-glutarate dehydrogenase $(28 \%)$ showed only one band of positivity at $45 \mathrm{kDa}$, corresponding to the E2 component of this multienzyme complex. ${ }^{810}$ Only two primary biliary cirrhosis sera that were antimitochondrial antibody positive by immunofluorescence were negative with both pyruvate and oxo-glutarate dehydrogenases. When tested with beef-heart mitochondria both of them reacted at $51 \mathrm{kDa}$. It is possible that this band corresponds to the E2 component of branchedchain 2-oxo acid dehydrogenase complex. This antigen complex does not encompass any of the specific epitopes of pyruvate dehydrogenase. ${ }^{23}$
Over a 2 year period 34 consecutive new patients who were antimitochondrial antibody positive as assessed by immunofluorescence were observed at our immunology laboratory. Only 18 of them had unequivocal primary biliary cirrhosis. This confirms that the antimitochondrial antibody test alone (by standard immunofluorescence) is not specific enough to diagnose primary biliary cirrhosis. Eighteen of 21 patients confirmed positive by immunoblotting had primary biliary cirrhosis. The positive predictive value of a positive antimitochondrial antibody test by immunoblotting is therefore extremely high $(86 \%)$. It must be stressed that the immunofluorescence pattern of antimitochondrial antibody positive patients was indistinguishable between immunoblotting negative and positive cases. Other reports have shown high specificity for primary biliary cirrhosis of antibodies to mitochondrial dehydrogenase complexes as detected by immunoblotting and ELISA. ${ }^{10-13}$ Only one study, however, ${ }^{10}$ examined sera from antimitochondrial antibody positive non-primary biliary cirrhosis patients. No details were given about clinical features and criteria of selection of this control group, which was tested only for pyruvate dehydrogenase.

Our findings strongly suggest that immunoblotting with commercially available oxo-acid dehydrogenases is a reproducible method for detection of antimitochondrial antibodies highly specific for primary biliary cirrhosis. It is not susceptible to observer biases and should be used in the clinical immunology laboratory as a discriminatory diagnostic test in all cases that are antimitochondrial antibody positive by immunofluorescence.

1 Kaplan MM. Primary biliary cirrhosis. N Engl f Med 1987; 316: $521-8$.

2 Walker JG, Doniach D, Roitt IM, Sherlock S. Serological tests in diagnosis of primary biliary cirrhosis. Lancet 1965; i: 82731 .

3 Berg PA, Klein R. Heterogeneity of antimitochondrial antibodies. Sem Liv Dis 1989; 9: 103-16.

4 Berg PA, Klein R, Lindenborn-Fotinos J. Antimitochondrial antibodies in primary biliary cirrhosis. $\mathcal{F}$ Hepatol $1986 ; 2$. 123-31

5 Gershwin ME, Mackay IR, Sturgess A, Coppel RL. Identification and specificity of a cDNA encoding the $70 \mathrm{kD}$ mitochondrial antigen recognized in primary cirrhosis. $\mathcal{F}$ mitochondrial antigen recogniz

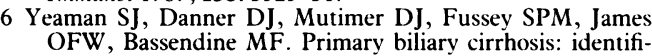
cation of two major $\mathrm{M} 2$ mitochondrial autoantigens. Lancet 1988; i: 1067-70.

7 Fussey SPM, Guest JR, James OFW, Bassendine MF, Yeaman SJ. Identification and analysis of the major $M 2$ autoantigens in primary biliary cirrhosis. Proc Natl $\mathrm{Acad} \mathrm{Sci}$ USA 1988; 85: 8654-8.

8 Fregeau DR, Prindiville T, Coppel RL, Kaplan M, Dickson ER, Gershwin ME. Inhibition of a-ketoglutarate dehydrogenase activity by a distinct population of autoantibodies recognizing dihydrolipoamide succinyltransferase

9 Fregeau DR, Roche TE, Davis PA, Coppel R, Gershwin ME. Primary biliary cirrhosis: inhibition of pyruvate dehydrogenase complex activity by autoantibodies specific for Ela, a non-lipoic acid containing mitochondrial enzyme. F I mmunol
1990; 144: 1671-6.

10 Yoshida T, Bonkovsky H, Ansari A, Danner D. Antibodies against mitochondrial dehydrogenase complexes in primary biliary cirrhosis. Gastroenterology 1990; 99: 187-94.

11 Van de Water J, Cooper A, Surh CD, Coppel R, Danner RD, Ansari A, et al. Detection of autoantibodies to recombinant mitochondrial proteins in patients with primary biliary cirrhosis. N Engl F Med 1989; 320: 1377-80.

12 Heseltine L, Turner IB, Fussey SPM, Kelley PJ, James OFW, Yeaman SJ, Bassendine MF. Primary biliary cirrhosis: quantitation of autoantibodies to purified mitochondrial enzymes and correlation with disease progression. Gastroenterologv 1990; 99: 1786-92. 
13 Leung PSC, Iwayama T, Prindiville T, et al. Use of designer recombinant mitochondrial antigens in the diagnosis of primary biliary cirrhosis. Hepatology 1992; 15: 367-72.

14 Klein R, Berg PA. Anti-M4 antibodies in primary biliary cirrhosis react with sulphite oxidase, an enzyme of the mitochondrial inter-membrane space. Clin Exp Immunol $1991 ; 84: 445-8$.

15 Klein R, Berg PA. Anti-M9 antibodies in sera from patients with primary biliary cirrhosis recognise an epitope of glycogen phosphorylase. Clin Exp Immunol 1990; 81: 65-71.

16 Leevy CM, Popper H, Sherlock S. Diseases of the liver and biliary tract. Standardization of nomenclature, diagnostic criteria and diagnostic methodology. Fogarty International Criteria and diagnostic methodo

17 Laemmli U. Cleavage of structural proteins during the assembly of the head of bacteriophage T4. Nature 1970;277: $680-5$

18 Towbin H, Stahelin T, Gordon J. Electrophoretic transfer of proteins from polyacrylamide gels to nitrocellulose sheets: procedures and some applications. Proc Natl Acad Sci USA 1979; 76: 4350-4.

19 Munoz LE, Thomas HC, Scheuer PJ, Doniach D, Sherlock S Is mitochondrial antibody diagnostic of primary biliary cirrhosis? Gut 1981; 22: 136-40.

20 Mitchison HC, Bassendine M, Hendrick A, Bennett MK, Bird G, Watson AJ, James OFW. Positive antimitochondrial antibody but normal alkaline phosphatase: is this primary biliary cirrhosis? Hepatology 1986; 6: 1279-84

21 Triger DR, Charlton CAC, Ward AM. What does the antimitochondrial antibody mean? Gut 1982; 23: 814-8.

22 Berg PA, Klein R. Mitochondrial antigens and autoantibodies: from anti-M1 to anti-M9. Klin Wochenschr 1986; 64: 897909.

23 Fussey SPM, Lindsay JG, Fuller C, Perham RN, Dale S, James OFW, et al. Autoantibodies in primary biliary cirrhosis: analysis of reactivity against eukaryotic and prokaryotic 2-oxo acid dehydrogenase complexes. Hepato$\log y$ 1991; 13: 467-74. 